\title{
Deafness-onychodystrophy syndrome
}

INSERM

\section{Source}

INSERM. (1999). Orphanet: an online rare disease and orphan drug data base. Deafnessonychodystrophy syndrome. ORPHA:3231

Deafness-onychodystrophy syndrome is a group of rare, genetic, developmental defect during embryogenesis disorders characterized by the association of sensorineural deafness and onychodystrophy (e.g. absent/hypoplastic finger and toenails), as well as brachydactyly and finger-like thumbs. Additional features present in one of the diseases comprising this group include osteodystrophy, intellectual disability, seizures, developmental delay, and distinctive facies. 